\begin{tabular}{|c|c|c|c|c|c|}
\hline SRA (India) & $=3.117$ & SIS (USA) & $=0.912$ & ICV (Poland) & $=6.630$ \\
\hline ISI (Dubc & $=0.829$ & РИНЦ (Russia & $=0.156$ & PIF (India) & $=1.940$ \\
\hline IF (Australia) & $=0.56$ & ESJI (KZ) & $=8.716$ & IBI (India) & $=4.260$ \\
\hline IF & $=1.500$ & SJIF (Morocco & $=5.667$ & ОАJI (USA) & $=0.350$ \\
\hline
\end{tabular}

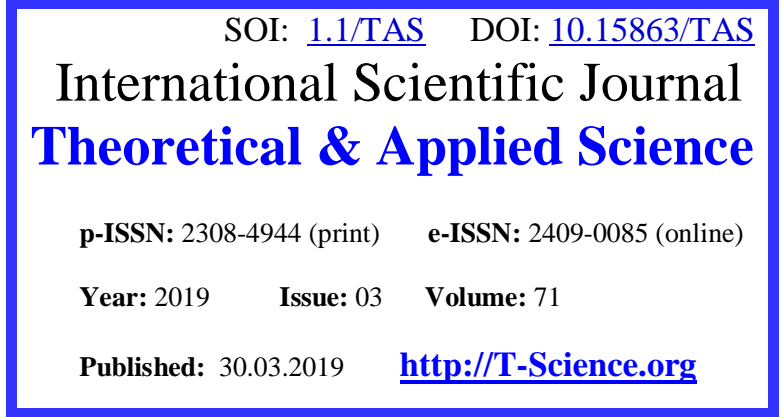

SECTION 19. Management. Marketing. Public administration.
QR - Issue

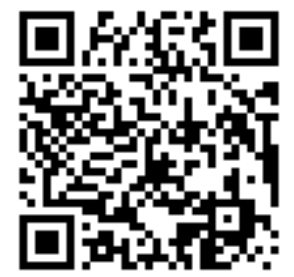

Javahir Javanshir Allahverdiyeva

Dissertant of Center of Agricultural Research of the Ministry of Agriculture of Azerbaijan Republic Baku, Azerbaijan Republic

\title{
PROBLEMS AND PROSPECTS OF DEVELOPMENT OF THE MARKET OF GRAIN PRODUCTS OF AZERBAIJAN IN MODERN CONDITIONS
}

Abstract: The problems and prospects for the development of the grain market of Azerbaijan in modern conditions are studied in the article. The main problems and trends in the global grain market are analyzed, the essence of global food problems is revealed with this purpose. The current state and problems of the production of grain products in Azerbaijan in the context of ensuring the food security of the population are considered. The level and dynamics of production and formation of stocks of grain products are investigated. Separately, the problems of ensuring the demand for wheat at the expense of domestic production and minimizing dependence on imports are considered. The problems of ensuring the dynamism and intensity of the grain market with consideration of the global food challenges are considered. The importance of the use of the latest technologies and progressive methods of technologies to increase the productivity of grain products in Azerbaijan is noted. The necessity of improving the existing mechanisms, including government regulation to stimulate the growth of wheat production and increase its stocks, is substantiated. A number of proposals and recommendations on the problems and prospects of development of the grain production market of Azerbaijan in modern conditions are summarized and given.

Key words: grain market, problems of self-sufficiency in grain products, problems of increasing the growth of wheat production in Azerbaijan, problems of formation of stocks of grain products in Azerbaijan, mechanisms to improve the state policy on grain products in Azerbaijan, prospects for the development of the market of grain products in Azerbaijan.

Language: Russian

Citation: Allahverdiyeva, J. J. (2019). Problems and prospects of development of the market of grain products of Azerbaijan in modern conditions. ISJ Theoretical \& Applied Science, 03 (71), 517-524.

Soi: http://s-o-i.org/1.1/TAS-03-71-49 Doi: roskef https://dx.doi.org/10.15863/TAS.2019.03.71.49

\section{ПРОБЛЕМЫ И ПЕРСПЕКТИВЫ РАЗВИТИЯ РЫНКА ЗЕРНОВОЙ ПРОДУКЦИИ АЗЕРБАЙДЖАНА В СОВРЕМЕННЫХ УСЛОВИЯХ}

Аннотация: В статье исследованы проблемы и перспективы развития рынка зерновой продукции Азербайджана в современных условиях. С этой целью анализированы основные проблемы и тенденции на мировом рынке зерна, раскрыта сущность глобальных продовольственных проблем. Рассмотрено современное состояние и проблемы производства зерновой продукции в Азербайджане в контексте обеспечения продовольственной безопасности населения страны. Исследован уровень и динамика производства и формирования запасов зерновой продукиии. Отдельно рассмотрень проблемы обеспечения потребностей в пиенице за счет внутреннего производства и минимизации зависимости от импорта. Рассмотрены проблемы обеспечения динамичности и интенсивности рынка зерновой продукции с учетом глобальных продовольственных вызовов. Отмечена важность применения новейших технологий и прогрессивных методов в повышении производительности зерновой продукции в Азербайджане. Обоснована необходимость совершенствования существующих механизмов государственного регулирования для стимулирования роста производства пшенищы и увеличения ее запасов. Обобщен и дан ряд предложений и рекомендаций по проблемам и перспективам развития рынка зерновой продукции Азербайджана в современных условиях.

Ключевые слова: рынок зерновой продукиии, проблемы самообеспечения государства зерновой продукией, проблемы повышения роста производства пшеницы в Азербайджане, проблемы формирования 


\begin{tabular}{|c|c|c|c|c|c|c|}
\hline \multirow{4}{*}{ Impact Factor: } & ISRA (India) & $=3.117$ & SIS (USA) & $=0.912$ & ICV (Poland) & $=6.630$ \\
\hline & ISI (Dubai, UAE & $=0.829$ & РИНЦ (Russia & $=0.156$ & PIF (India) & $=1.940$ \\
\hline & GIF (Australia) & $=0.564$ & ESJI (KZ) & $=8.716$ & IBI (India) & $=4.260$ \\
\hline & JIF & $=1.500$ & SJIF (Morocco & $=5.667$ & OAJI (USA) & $=0.350$ \\
\hline
\end{tabular}

запасов зерновой продукции в Азербайджане, механизмы совериенствования государственной политики относительно зерновой продукиии в Азербайджане, перспективы развития рынка зерновой продукции в Азербайджане.

\section{Introduction}

В условиях роста глобальных воздействий растут проблемы обеспечения населения мира основными видами продовольственной продукции. По данным специализированных структур ООН, в мире более 820 млн. человек недоедают и испытывают проблемы голода. Сотни миллионов людей не имеют возможности приобрести необходимые виды важной продовольственной продукции [1]. Более того, изза засухи растет проблема по выращиванию и формированию запасов зерновой продукции, особенно пшеницы. Большинство стран мира не в состоянии обеспечить себя зерновой продукцей и зависят от импортозамещения. Всё это обуславливает мобилизацию усилий международных организаций и ведущих стран мира по облегчению нарастающих глобальных продовольственных проблем, и стимулирует их найти более действенные, продуктивные механизмы стабилизации ситуации на рынке зерновой продукции в мире. К сожалению, производство и формирование запасов зерновой продукции не зависит от возможностей отдельных стран и, во-многом, ситуация осложнена климатическими условиями в мире, в частности, глобальным потеплением. Кроме того, из общего объема мирового зерна - более 2,5 трлн. тонн - на мировой рынок поступает всего около $16 \%$. В структуре мировой торговли зерновой продукцией основное место занимает пшеница, на долю которой приходится 44 \% мировой торговли [2, c.75]. Кроме того, многие страны уменьшают с каждым годом объем экспорта и тем самым стараются усилить свои зерновые запасы для укрепления продовольственной безопасности своего населения. Безусловно, все эти тенденции создают беспокойство относительно роста глобальных проблем продовольствия, но прежде всего, проблем обеспечения населения зерновой продукцией.

\section{Materials and Methods}

Отметим, что вопросы интенсификации и повышения эффективности производства зерновой продукции и рынка зерна рассмотрены в научных трудах и работах ряда ученых. В первую очередь хотели бы отметить ряд научных работ, которые последовательно занимались проблемами развития сельского сектора и аграрных сфер, в которых формируются сырьевые ресурсы и основы производства важных видов продовольствия. В трудах Э.Диаз-Бонилла рассмотрены макроэкономические проблемы развития аграрной сферы и продовольственной безопасности [3]. Основной упор делается на повышение эффективности специальных программ по повышению объема продовольственной продукции за счет увеличения производительности, применения новейших технологий и подходов. Далее отмечается важность совершенствования экономической основы развития сфер, вырабатывающих продовольственную продукцию с целью обеспечения доступности важных видов продовольственной продукции для населения мира [4]. Для этого международные организации и государства мира должны скоординировать деятельность по регулированию зернового рынка в мире, обозначить его фундаментальные проблемы и найти более приемлемые решения по их устранению. Все это обуславливает разработку и реализацию крупных инвестиционных проектов по расширению производства зерна в мире и формированию достаточного резерва зерновой продукции [5]. Исследователи Р.С.Максимов, Н.Е.Евдокимова, Н.И.Пыжикова, Т.К.Абдуллаева, С.А.Высочкина, О.А.Бурлакова, Н.В.Мешков и А.А.Парутин рассматривали важные проблемы и перспективы развития рынка зерна с учетом интенсификации роста его сырьевой базы, обеспечения модернизации хозяйственных структур, производящих зерновую продукцию, проблем специализации, организации и регулирования рынка зерна, создания эффективных механизмов по рассматриваемым проблемам и тем самым усиления потенциала зерновых рынков для стабилизации процессов обеспечения населения основными видами продовольственной продукции. Зерно является важнейшим стратегическим товаром, производство, обращение и потребление которого выступает важным фактором стабильности национальной экономики и основой продовольственной безопасности страны [6]. В нынешних условиях в связи с усилением глобальных воздействий и внешних факторов необходим переход к многоуровневой системе совершенствования основных механизмов рынка зерна с обеспечением взаимных интересов всех участников данного рынка. В настоящее время проблемы обеспечения населения продовольственной продукцией, особенно пшеницей, имеют стратегическую важность и напрямую связаны с продовольственной безопасностью страны. Главными проблемами зернового рынка являются нестабильность выращивания и роста производства зерновой продукции, резкие колебания цен, другие внешние и внутренние факторы, влияющие на 


\begin{tabular}{|c|c|c|c|c|c|c|}
\hline \multirow{4}{*}{ Impact Factor: } & ISRA (India) & $=3.117$ & SIS (USA) & $=0.912$ & ICV (Poland) & $=6.630$ \\
\hline & ISI (Dubai, UAE & $=0.829$ & РИНЦ (Russia & $=0.156$ & PIF (India) & $=1.940$ \\
\hline & GIF (Australia) & $=0.564$ & ESJI (KZ) & $=8.716$ & IBI (India) & $=4.260$ \\
\hline & JIF & $=1.500$ & SJIF (Morocco & $=5.667$ & OAJI (USA) & $=0.350$ \\
\hline
\end{tabular}

макроэкономическую нестабильность, инфляция, социально-экономическая напряженность в стране и т.д. Для решения данных проблем требуется разработка системы эффективных регуляторов зернового рынка и обеспечение адаптации основных методов регулирования к меняющимся экономическим ситуациям и процессам [7]. Кроме того, для развития рынка зерна и зерновых продуктов требуется активное внедрение инновационных технологий, современных методов управления производством и формированием запасов зерновой продукции. Ключевыми механизмами по повышению мотивации субъектов рынка зерна и производителей зерновых продуктов является высокая ликвидность произведенной продукции и поддержание цен на адекватном уровне с помощью государственной поддержки и регулирования [8].

Следует подчеркнуть, что в современных условиях зерно и зерновая продукция являются стратегическими компонентами и элементами продовольственной и национальной безопасности страны. Через зерновой рынок происходит приравнивание объема и структуры зернового производства к объему общественной потребности в зерне, поддерживается взаимосвязь производителей и потребителей [9]. При этом зерновой рынок страны, имеющий многоцелевой и многофункциональный характер, сравнительно быстро прошел путь от жесткого регулирования государства до практически его устранения [10]. Для сбалансирования деятельности рынка зерна и его субъектов требуется максимально совершенствовать законодательную базу в этой сфере, модифицировать важные организационноэкономические механизмы, обновить инструментарий их функционирования [11]. Рассогласованность основных механизмов государственной поддержки, воздействий инвестиционно-инновационной среды и прочих ключевых вопросов, имеющих воздействие на развитие рынка зерна, приводит к снижению обеспеченности населения продуктами питания и формируют реальную угрозу для продовольственной безопасности страны [12]. В своих исследованиях А.А.Парутин особое внимание обратил на совершенствование важных механизмов, методов и инстументов управления хозяйствующими субъектами зернового рынка с учетом современных реалий и перспектив развития данной сферы [13].

На Рисунке 1 даны основные элементы и функции формирования и развития рынка зерна в совремнных условиях. 


\begin{tabular}{|c|c|c|c|c|c|c|}
\hline \multirow{4}{*}{ Impact Factor: } & ISRA (India) & $=3.117$ & SIS (USA) & $=0.912$ & ICV (Poland) & $=6.630$ \\
\hline & ISI (Dubai, UAE & $=0.829$ & РИНЦ (Russia) & $=0.156$ & PIF (India) & $=1.940$ \\
\hline & GIF (Australia) & $=0.564$ & ESJI (KZ) & $=8.716$ & IBI (India) & $=4.260$ \\
\hline & JIF & $=1.500$ & SJIF (Morocco & $=5.667$ & OAJI (USA) & $=0.350$ \\
\hline
\end{tabular}

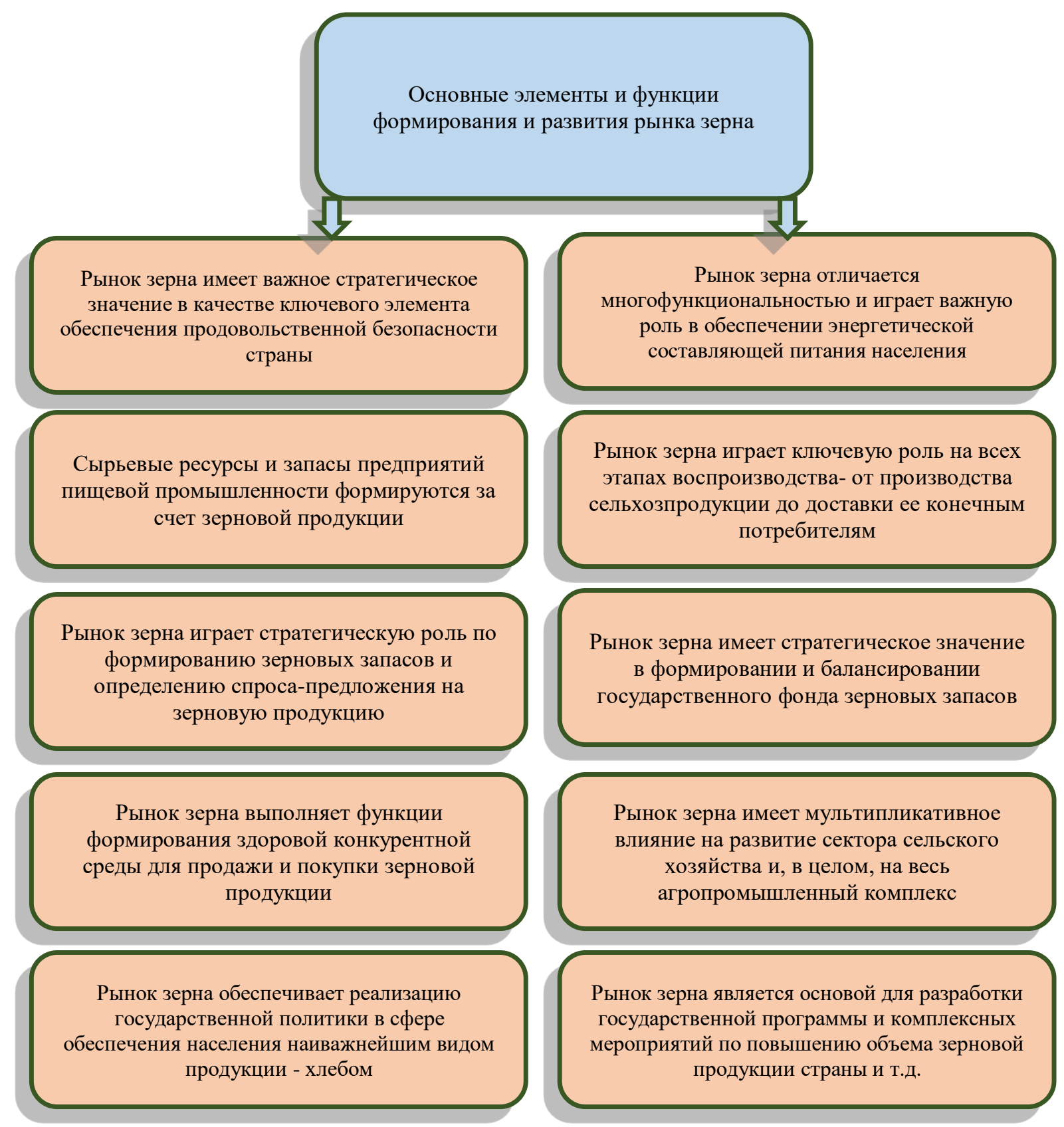

\section{Рисунок 1. Блок-схема основных элементов и функций формирования и развития рынка зерна (подготовлена автором на основе материалов исследования).}

Отметим, что в Азербайджане вопросы формирования рынка зерновой продукции, а также проблемы повышения эффективности и производительности зерновой продукции находятся под пристальным вниманием государства. Были приняты соответствующие законодательные акты и практичные механизмы по развитию разных сфер сельскохозяйственного сектора и деятельности агропромкомплекса [14]. За последнее десятилетие были разработаны и внедрены множественные механизмы и инструменты по государственной поддержке производителей сельхозпродукции и владельцев аграрных предприятий. Формируются современные агропромышленные парки и крупные фермерские, сельскохозяйственные предприятия. Особое внимание уделяется развитию аграрной сферы на научной основе и для этого в стране имеется серьезный потенциал. Так, под руководством академика Д.А.Алиева разрабатывались продуктивные сорта зерна, которые применялись не только в Азербайджане, но и в других странах мира [15]. В стране создана надежная система продовольственного обеспечения и все вопросы, связанные с производством, формированием запасов и 


\begin{tabular}{|c|c|c|c|c|c|c|}
\hline \multirow{4}{*}{ Impact Factor: } & ISRA (India) & $=3.117$ & SIS (USA) & $=0.912$ & ICV (Poland) & $=6.630$ \\
\hline & ISI (Dubai, UAE & $=0.829$ & РИНЦ (Russia) & $=0.156$ & PIF (India) & $=1.940$ \\
\hline & GIF (Australia) & $=0.564$ & ESJI (KZ) & $=8.716$ & IBI (India) & $=4.260$ \\
\hline & JIF & $=1.500$ & SJIF (Morocco & $=5.667$ & OAJI (USA) & $=0.350$ \\
\hline
\end{tabular}

развитием рынков продовольственной продукции имеют стратегическое значение [16]. Создан Государственный Фонд Зерна, который должен сыграть стабилизирующую роль на рынке зерновой продукции страны и обеспечить баланс зерновых запасов с учетом спроса и предложения на нем [17]. Постоянно совершенствуются регулирующие механизмы аграрной сферы и проводятся целенаправленные работы по повышению эффективности аграрного сектора страны [18; 19]. Все эти последовательные мероприятия оказали положительное влияние на усиление продовольственной безопасности страны и повысили надежность применяемых механизмов по обеспечению населения важными видами продовольственной продукции [20].

Следует подчеркнуть, что определены стратегические цели и приоритетные направления развития аграрной сфере страны на ближайший и долгосрочный период, которые отражены в Стратегических дорожных картах о производстве и переработке сельскохозяйственной продукции в Азербайджанской Республике, утвержденных Указом Президента Азербайджанской Республики от 6 декабря 2016 года [21]. В стране осуществляются стратегические подходы к обеспечению важными видами продовольственной продукции и принимаются системные меры по укреплению продовольственной безопасности страны путем роста продовольственной продукции и расширения структуры зерновой продукции. В связи с этим профессор Б.Х. Аташов отмечает, что границы продовольственной безопасности страны обеспечиваются тогда, когда $90 \%$ необходимого объема продовольствия и сырьевых ресурсов для производства основных видов продовольственной продукции обеспечиваются за счет местных производителей [22]. Профессор Э.А.Гулиев справедливо подчеркивает, что для формирования необходимого уровня продовольственных запасов требуется в корне совершенствовать основные механизмы производства зерна и развития рынка зерновой продукции [23].

На Рисунке 2 дан общий объем сбора зерна в Азербайджанской Республике за 20002017 гг.

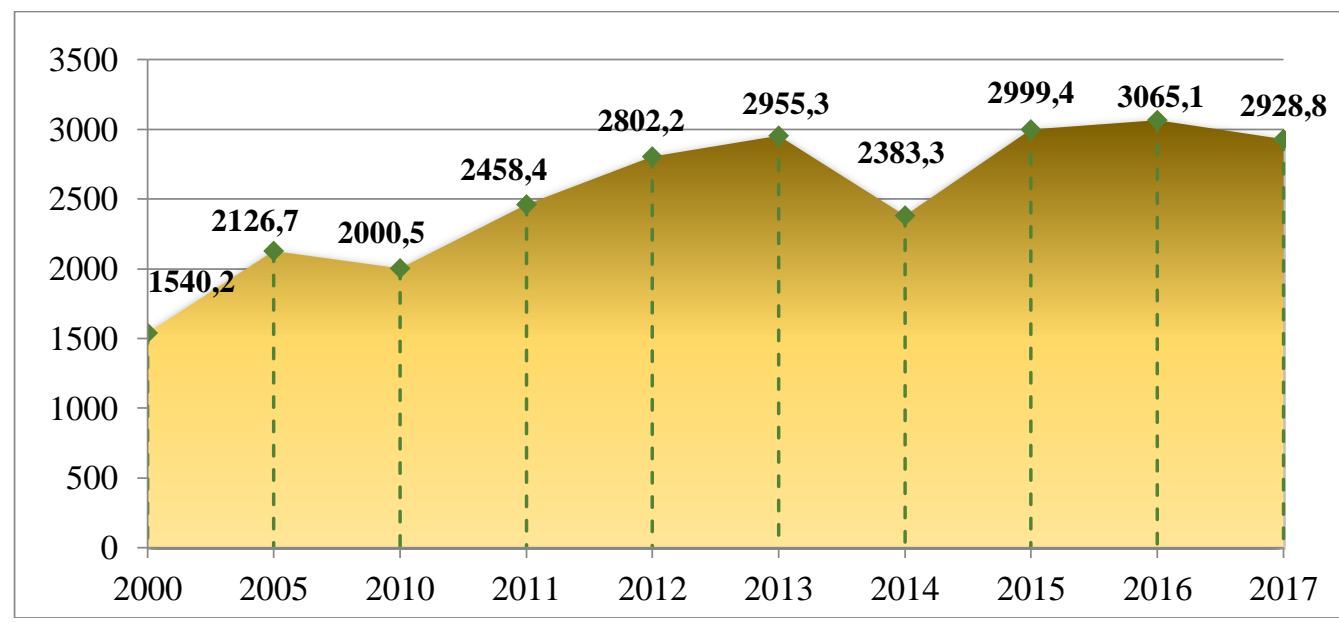

Рисунок 2. Общий объем сбора зерна в Азербайджанской Республике, тыс. тонн. 2000-2017 гг. (подготовлено автором по материалам Государственного Статистического Комитета Азербайджанской Республики - http://stat.gov.az).

Как видно из Рисунка 2, за период 2000-2017 гг. общий объем сбора зерна в Азербайджане вырос на 90 \% и по итогам 2017-го года составил 2928,8 тыс. тон, однако за последние годы существенный рост сбора зерна не наблюдается. Bсе это обуславливает применение действенных мер с целью повышения эффективности проводимой государственной политки по регулированию рынка зерновой продукции и оказанию государственной поддержки субъектам зерноводства.

На Рисунке 3 дана общая динамика производства зерновых культур и пшеницы за 2003-2017 гг. 


\begin{tabular}{|c|c|c|c|c|c|c|}
\hline \multirow{4}{*}{ Impact Factor: } & ISRA (India) & $=\mathbf{3 . 1 1 7}$ & SIS (USA) & $=0.912$ & ICV (Poland) & $=6.630$ \\
\hline & ISI (Dubai, UAE & $=0.829$ & РИНЦ (Russia & $=0.156$ & PIF (India) & $=1.940$ \\
\hline & GIF (Australia) & $=0.564$ & ESJI (KZ) & $=8.716$ & IBI (India) & $=4.260$ \\
\hline & JIF & $=1.500$ & SJIF (Morocce & $=5.667$ & OAJI (USA) & $=0.350$ \\
\hline
\end{tabular}

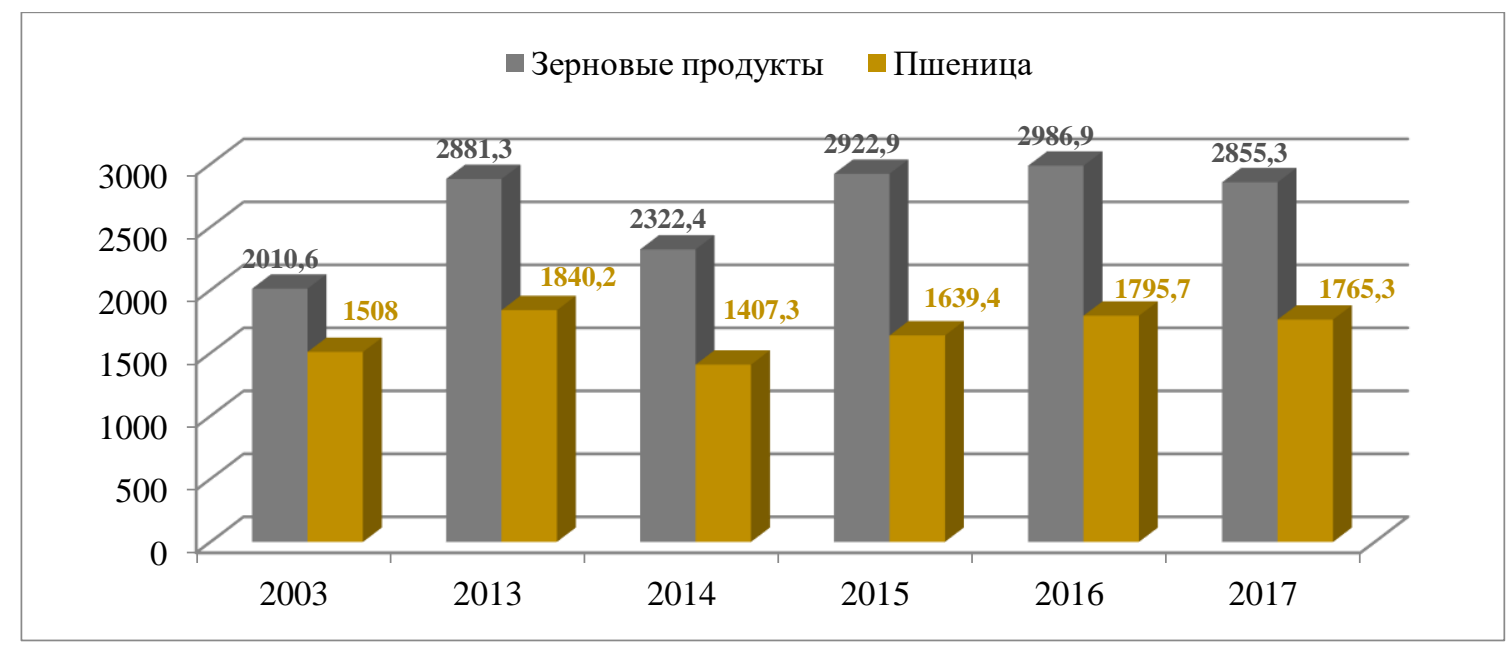

Рисунок 3. Производство зерновых культур и пшеницы за 2003-2017 гг. (подготовлено автором по материалам Государственного Статистического Комитета Азербайджанской Республики http://stat.gov.az).

Если анализировать Рисунок 3, то видно, что за период 2003-2017 гг. рост производства зерновых культур в Азербайджане вырос на 42 \% и в 2017 году составил 2855,3 тыс. тон. Что касается производства пшеницы, то за последние 3 года особый рост не наблюдается, а в 2017 году объем производства пшеницы в стране был на уровне 1765,3 тыс. тон. Эти факторы не позволяют сформировать необходимый запас зерна в фонде страны и, таким образом, обуславливают необходимость импорта данной стратегической продукции. Так, за 2007-2017 гг. уровень самообеспеченности страны пшеничной продукцией колебался от 48 \% до 58,1\%, то есть для полного обеспечения потребности населения в данной продукции Азербайджан импортировал пшеницу из-за рубежа в этот период. Все это отражено на Рисунке 4, в котором дана динамика уровня самообеспеченности пшеничной продукцией в Азербайджнской Республики за 2003-2017 гг.

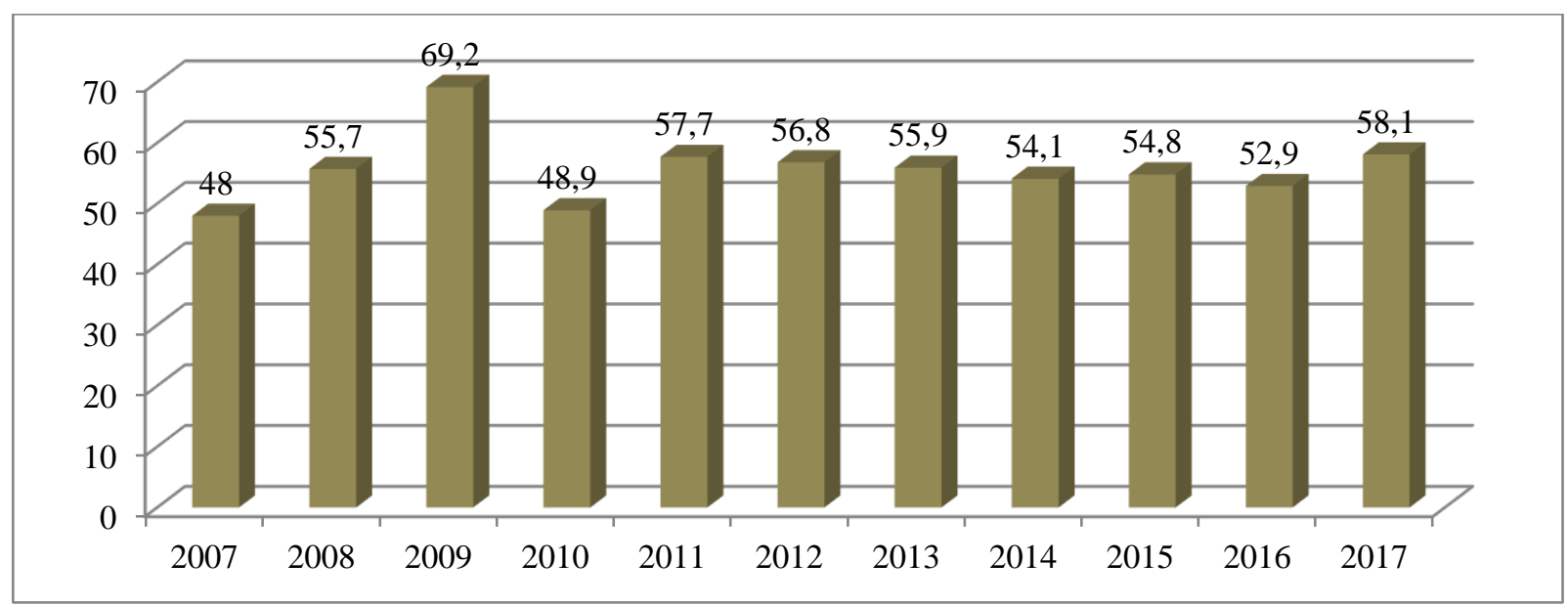

Рисунок 4. Динамика уровня самообеспеченности пшеничной продукцией в Азербайджанской

Республики за 2003-2017 гг., в \%-х (подготовлено автором по материалам Государственного Статистического Комитета Азербайджанской Республики - http://stat.gov.az).

А на Рисунке 5 отдельно отражен уровень импортозависимости Азербайджанской Республики зерновой продукции в целом, и пшеницы в частности за 2007-2017 гг., на котором видно, что импортозависимость зерновой продукции в 2007 году составила 43 \%, пшеницы - $52 \%$, а в 2017 году данные показетли были на уровне $33,1 \%$ и 41,9\% соответственно. 


\begin{tabular}{|c|c|c|c|c|c|c|}
\hline \multirow{4}{*}{ Impact Factor: } & ISRA (India) & $=3.117$ & SIS (USA) & $=0.912$ & ICV (Poland) & $=6.630$ \\
\hline & ISI (Dubai, UAE & $=0.829$ & РИНЦ (Russia & $=0.156$ & PIF (India) & $=1.940$ \\
\hline & GIF (Australia) & $=0.564$ & ESJI (KZ) & $=8.716$ & IBI (India) & $=4.260$ \\
\hline & JIF & $=1.500$ & SJIF (Morocco & $=5.667$ & OAJI (USA) & $=0.350$ \\
\hline
\end{tabular}

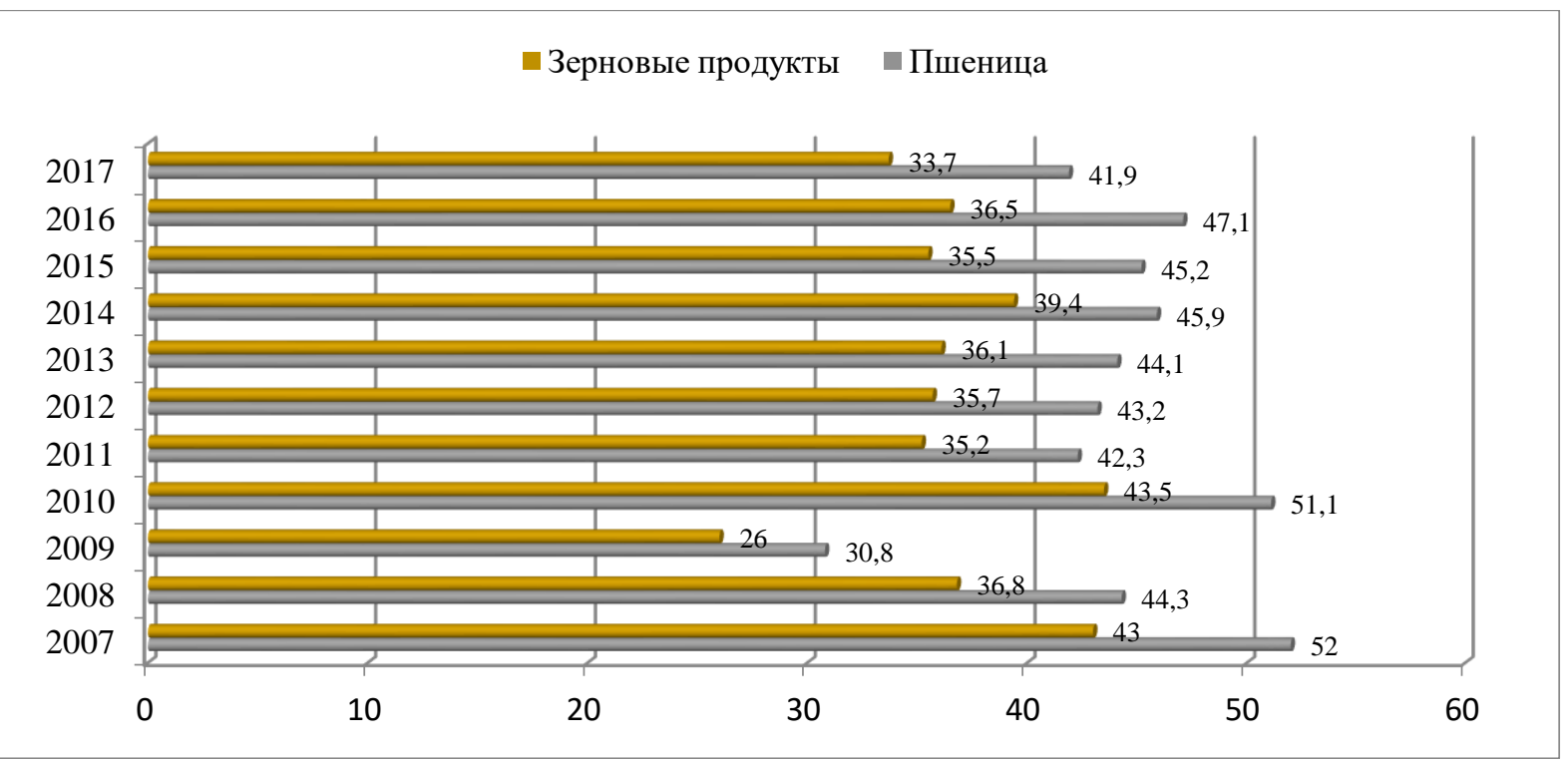

Рисунок 5. Уровень импортозависимости зерновой продукции и пшеницы Азербайджнской Республики за 2007-2017 гг, в \% (подготовлено автором по материалам Государственного Статистического Комитета Азербайджанской Республики - http://stat.gov.az).

На Рисунке 6 отражена динамика импорта пшеницы Азербайджана за 2013-2017 гг. и за этот период эти показатели были в пределах 1,2-1,6 млн. тон в год.

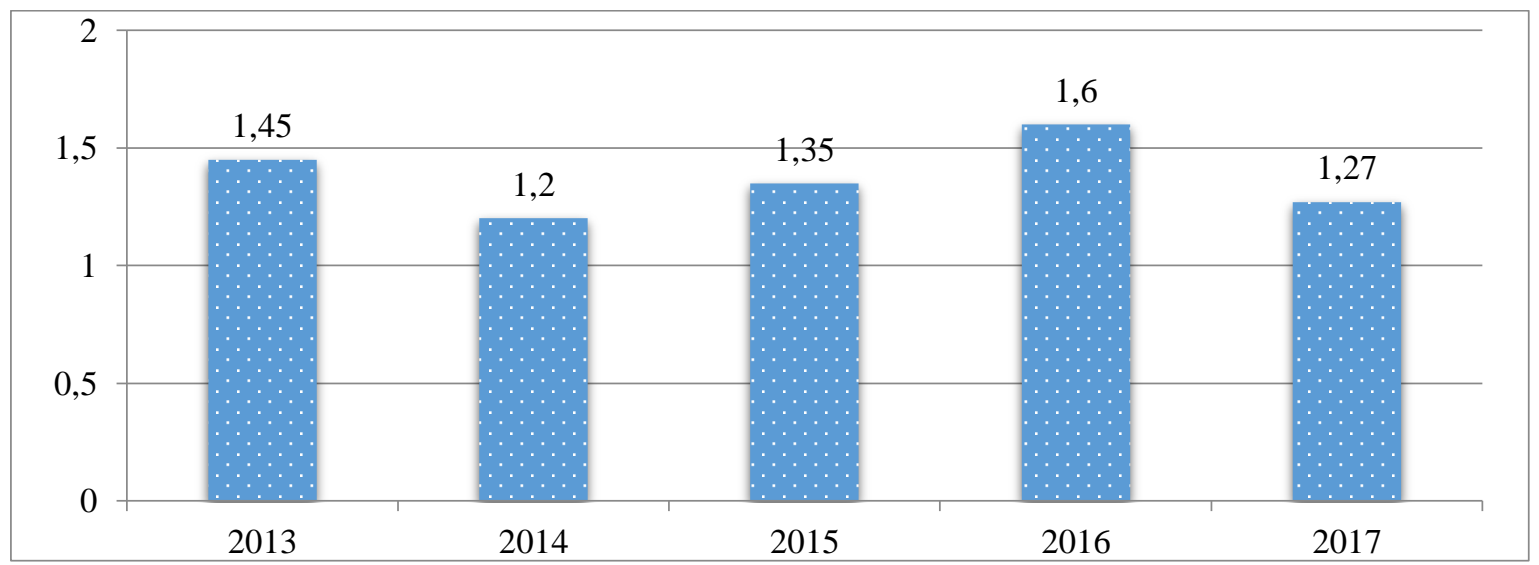

Рисунок 6. Динамика импорта пшеницы Азербайджана за 2013-2017 гг., млн. тон (подготовлено автором по материалам Государственного Статистического Комитета Азербайджанской Республики - http://stat.gov.az).

\section{Conclusion}

Таким образом, в ближайшей перспективе в Азербайджане будет усилена работа по интенсификации развития рынка зерновой продукции, в которой основной упор направлен на повышение производительности важных видов зерновой продукции и эффективности формирования рынка зерна, применение новейших технологий с учетом международного опыта и усиление внешнеторговой деятельности для выхода Азербайджана на региональные и мировые рынки и т.д. 


\begin{tabular}{|c|c|c|c|c|c|c|}
\hline \multirow{4}{*}{ Impact Factor: } & ISRA (India) & $=\mathbf{3 . 1 1 7}$ & SIS (USA) & $=0.912$ & ICV (Poland) & $=6.630$ \\
\hline & ISI (Dubai, UAE & $=0.829$ & РИНЦ (Russia & $=0.156$ & PIF (India) & $=1.940$ \\
\hline & GIF (Australia) & $=0.564$ & ESJI (KZ) & $=8.716$ & IBI (India) & $=4.260$ \\
\hline & JIF & $=1.500$ & SJIF (Morocce & $=5.667$ & OAJI (USA) & $=0.350$ \\
\hline
\end{tabular}

\section{References:}

1. (n.d.). Agricultural And Food Marketing. Retrieved 2019, from http://www.fao.org

2. Ahmadulina, T. V., \& Raspopov, V. M. (2018). Osobenennosti razvitija sovremennogo mirovogo rynka zerna. Mezhdunarodnaja jekonomika, №3, 73-81.

3. Diaz-Bonilla, E. (2015). Macroeconomics, Agriculture and Food Security. (p.612). Washington D.C.

4. Cooper, R. (n.d.). Re-discovering ancient wheat varieties as functional foods. Retrieved 2019, from https://www.ncbi.nlm.nih.gov

5. Bhandalkar, S., \& Das, D. (2018). Food Services and Hospitality. Global Opportunity Analysis and Industry Forecast 2018-2025. (p.263). https://www.alliedmarketresearch.com

6. Maksimov, R. S. (2008). Sovershenstvovanie struktury $i$ infrastruktury rossijskogo rynka zerna. Diss.kand.jekon.nauk. (p.159). Volgograd.

7. Evdokimova, N. E. (2011). Formirovanie jeffektivnogo mehanizma gosudarstvennogo regulirovanija rynka zerna. Diss.kand.jekon.nauk. (p.211). Moscow.

8. Pyzhikova, N. I. (2010). Razvitie rynka zerna $i$ zernoproduktov regiona. Diss. d-ra jekon. nauk. (p.279). Novosibirsk.

9. Abdullaeva, T. K. (2009). Formirovanie $i$ razvitie optovogo rynka sel'skohozjajstvennoj produkcii $i$ prodovol'stvija. Diss. d-ra jekon.nauk. (p.385). Michurinsk-naukograd.

10. Vysochkina, S. A. (2008). Razvitie rynka zerna $v$ rossijskom regione. Diss.kand.jekon.nauk. (p.194). Volgograd.

11. Burlakova, O. A. (2011). Organizacija $i$ regulirovanie rynka sel'skohozjajstvennoj produkcii. Diss.kand.jekon.nauk. (p.243). Saransk.

12. Meshkov, N. V. (2007). Organizacionnojekonomicheskij mehanizm funkcionirovanija regional'nogo rynka zerna: na materialah Altajskogo kraja. Diss. kand. jekon. nauk. (p.180). Novosibirsk.

13. Parutin, A. A. (2008). Metody i instrumenty upravlenija hozjajstvujushhimi sub\#ektami zernovogo rynka. (p.192). Diss.kand.jekon.nauk. Voronezh.

14. (2000). Zakon Azerbajdzhanskoj Respubliki o zerne. Baku, 16 ijunja 2000 god, № 898-IQ.

15. Aliev, D. A. (1959). Vlijanie mikrojelementov na nekotorye fiziologicheskie processy $i$ urozhajnost' ozimoj pshenicy. Primenenie mikrojelementov $\mathrm{v}$ sel'skom hozjajstve i medicine. (pp.335-339). Riga.

16. Guliev, J. A. (2013). Nadezhnaja sistemy prodovol'stvennogo obespechenija: problemy kooperacii $i$ integracii. Monografija. (p.308). Baku: Izd-vo «Elm».

17. (n.d.). Hranenie $i$ ispol'zovanie Gosudarstvennogo Fonda Zerna. Utverzhdeno resheniem Kabineta Ministrov Azerbajdzhanskoj Respubliki ot 7 ijulja 2009 goda.

18. Abbasov, V. H. (2017). Agrarnaja jekonomika. (p.468). Baku: Izd-vo «Ecopint».

19. Ibragimov, I. H. (2016). Jekonomika agrarnoj sfery. Monografija. (p.655). Baku.

20. Atashov, B. H. (2005). Akutal'nye problemy prodovol'stvennoj bezopasnosti. (p.336). Baku: Izd-vo «Elm».

21. (n.d.). Strategicheskie dorozhnye karty o proizvodstve i pererabotke sel'skohozjajtsvennoj produkcii $v$ Azerbajdzhanskoj Respublike. Utverzhdeno Ukazom Prezidenta Azerbajdzhanskoj Respubliki ot 6 dekabrja 2016 goda.

22. Atashov, B. H. (2017). Problemy struktury $i$ jeffektivnosti v agrarnoj sfere (teorija i praktika). (p.536). Baku: izd-vo «Kooperacija».

23. Guliev, J. A. (2018). Global'naja prodovol'svennaja bezopasnost': realii, vyzovy $i$ perspektivy. (p.480). Baku: izd-vo «Kooperacija».

24. (2018). Osnovnye jekonomicheskie pokazateli sel'skozjajstvennyh predprijatij $i$ predprijatij chastnyh predprinimatelej. Statisticheskoe izdanie. (p.330). Baku.

25. (2018). Prodovol'stvennyj balans Azerbajdzhana. Statisticheskoe izdanie. (p.96). Baku.

26. (2018). Sel'skoe hozjajtsvo Azerbajdzhana. Statisticheskoe izdanie. (p.612). Baku.

27. (2018). Statisticheskie pokazateli Azerbajdzhana. Statisticheskoe izdanie. (p.808). Baku.

28. (2018). Torgovlja $v \quad$ Azerbajdzhane. Statisticheskoe izdanie. (p.182). Baku.

29. (2018). Vneshnjaja torgovlja Azerbajdzhana. Statisticheskoe izdanie. (p.220). Baku. 